\title{
Transoral Endoscopic Thyroid Surgery: Indication, Preparation and Surgical Technique
}

\author{
Jun-Ook Park \\ Department of Otolaryngology Head and Neck Surgery, Inje University College of Medicine, Haeundae Paik Hospital, Busan, Korea
}

\section{갑상선 구강내시경 수술: 적응증, 준비 및 수술 방법}

박 준 욱

인제대학교 의과대학 이비인후과학교실

\author{
Received February 18, 2018 \\ Revised March 1, 2018 \\ Accepted March 3, 2018 \\ Address for correspondence \\ Jun-Ook Park, MD, PhD \\ Department of Otolaryngology Head \\ and Neck Surgery, Inje University \\ College of Medicine, \\ Haeundae Paik Hospital, \\ 875 Haeun-daero, Haeundae-gu, \\ Busan 48108, Korea \\ Tel $+82-51-797-2290$ \\ E-mail junook2000@paik.ac.kr
}

Natural orifice transluminal endoscopic surgery (NOTES) is the latest surgical technique for inserting an endoscope through the mouth, anus, vagina etc., and for performing surgery with mucosal incision only, i.e., without skin incision. Recently, a number of researchers have applied NOTES to thyroid surgery in several trials, with the aim of removing the thyroid gland through oral cavity. The transoral endoscopic thyroid surgery became widely known after Anuwong et al. reported successful results for their first 60 patients and it has become increasingly recognized as a feasible novel surgical procedure. The purpose of this article is to review and summarize the existing literature, and describe in detail the preoperative considerations, rationale for patient selection, surgical method and postoperative management for transoral thyroid surgery. Korean J Otorhinolaryngol-Head Neck Surg 2018;61(3):121-6

Key Words Endoscopic thyroidectomy · Minimally invasive $\cdot$ Thyroidectomy · Transoral endoscopic thyroidectomy · Transoral thyroidectomy.

\section{서 론}

자연 개구부 내시경 수술(natural orifice transluminal endoscopic surgery, NOTES)은 입, 항문, 질 등을 통해 내시경 을 삽입하고 피부 절개 없이 점막 절개만으로 수술을 수행하 는 최신 수술 기법이다. 최근에 많은 연구자들이 NOTES를 갑 상선 수술에 적용하여 구강을 통해 갑상선을 제거하고자 노력 을 해왔다. ${ }^{1)}$ 갑상선 구강내시경 수술(transoral endoscopic thyroid surgery)의 접근 경로는 크게 두 가지로 나눌 수 있다. 첫 번째는 설하 경로(sublingual route), 두 번째는 전정 경로 (vestibular route)이다. 지금까지 보고된 바에 의하면 설하 경 로는 조직 손상이 크고 합병증이 비교적 많았다. ${ }^{2-5)}$ 한편, 전 정 경로는 2016년에 Anuwong ${ }^{6}$ 이 60명의 환자에서 성공적인
결과를 보고한 이후에 널리 알려지게 되었다. 그는 수술 방법 을 정리하여 transoral endoscopic thyroidectomy vestibular approach(TOETVA)라고 명칭을 하였다. 다양한 국가의 많은 연구자들이 TOETVA 또는 이와 유사한 방법으로 수술을 시 도하고 성공적인 초기 결과를 보고하였다. ${ }^{7-14)} \mathrm{TOETVA}$ 는 전 세계의 여러 의사들이 많은 관심을 가지고 있으며 멀지 않은 미래에 갑상선 수술의 새로운 대안이 될 것으로 기대된다. 최 근에 국내에서도 이비인후과와 외과에서 갑상선 구강내시경 수술 또는 로봇 수술에 관심을 가지고 활발히 시행하고 있 다. 갑상선 구강내시경 수술을 시작하는 수술자를 위해 기존 문헌을 검토하여 수술 전 고려사항, 환자 선택, 수술 방법 및 술 후 관리에 대해 정리하고자 한다.

This is an Open Access article distributed under the terms of the Creative Commons Attribution Non-Commercial License (http://creativecommons.org/licenses/by-nc/4.0) which permits unrestricted non-commercial use, distribution, and reproduction in any medium, provided the original work is properly cited. 


\section{본 론}

\section{환자 선택}

갑상선 구강내시경 수술은 임상에서 사용된 지 얼마 되지 않은 최신의 수술 방법이므로 아직 명확한 적응증이나 금기 의 기준이 확립되지 않았으나, 최근 Razavi와 Russel1 ${ }^{15)}$ 은 영 어 기반의 문헌들을 검토하여 갑상선 구강내시경 수술의 적 응과 금기를 요약하여 발표하였다. 대다수의 저자들이 가장 중요한 적응증으로 '새로운 접근 경로를 통해 갑상선을 제거 하고자 하는 환자의 동의'라고 의견의 일치를 보였으나 절제 에 적합한 갑상선의 부피나 주요결절의 크기에 대해서는 아 직 충분한 합의가 이루어지지 않았다. 그들이 제시한 적응증 을 보면, 양성이거나 중등도인 경우(Bethesda II, III, IV)에 는 갑상선의 직경 $10 \mathrm{~cm}$ 미만과 결절 크기는 $6 \mathrm{~cm}$ 미만, 악성 이 의심되는 경우(Bethesda $\mathrm{V}, \mathrm{VI})$ 에는 주요결절 직경 $2 \mathrm{~cm}$ 미만으로 하였다. 그레이브스병을 가진 환자들도 적응증에 조심스럽게 포함시켰다. 한편, Anuwong 등 ${ }^{16)}$ 은 그의 다른 논문에서 양성종양이 의심되는 경우에는 약 $6 \sim 8 \mathrm{~cm}$ 이하일 경우에도 TOETVA의 대상이 될 수 있다고 하였다. 이전에 두

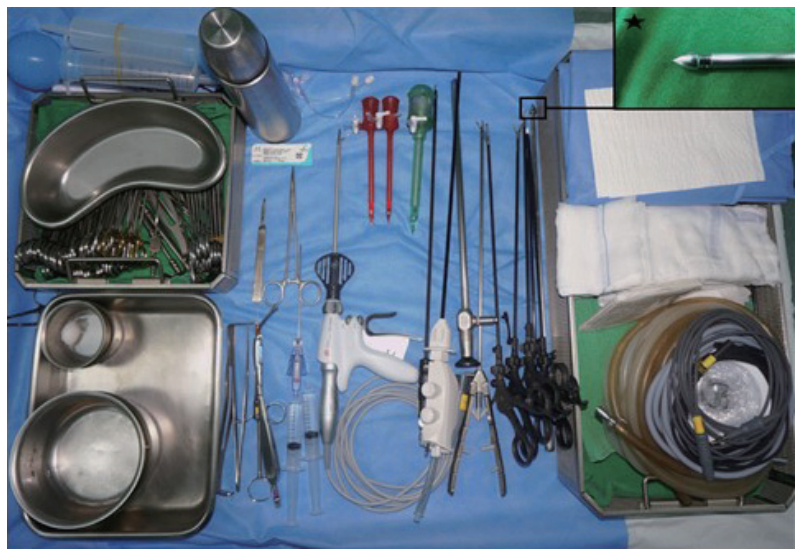

Fig. 1. The usual instruments for transoral endoscopic thyroid surgery. *vascular tunneller for creating and widening working space.
경부 수술이나 방사선 치료(종격동 포함)를 받은 환자, 전신 마취를 할 수 없는 환자, 급성 갑상선 기능 항진증, 반회후두 신경 마비, 갑상선 흥골하 확장, 수술 전 림프절 전이, 갑상선 외 확장, 구강 농양, 그리고 위에서 언급한 적응증을 만족하 지 않는 환자는 절대적 금기로 권고하였으며 상대적 금기는 하시모토 갑상선염과 비만으로 하였다. ${ }^{15)}$ 또 다른 연구에서 중심경부림프절 절제술은 예방적 관점(수술자를 포함한 의 료진이 중심경부림프절제로 얻는 병리학적 정보가 주는 이 득이 수술로 인한 위험보다 크다고 판단하는 경우)에서 혹은 치료적 관점(림프절 전이가 수술 도중에 새로 발견되었을 경 우)에서 시행할 수 있다고 하였다. ${ }^{17}$

\section{수술 기구}

직경 $10 \mathrm{~mm}, 30^{\circ}$ 경성 내시경을 일반적으로 사용한다. 일 반적인 내시경 기구에는 Babcock forceps, Johann forceps, right-angled forceps, short Maryland forceps, ultrasonic device 등을 사용한다. 기구 삽입을 위해 $5 \mathrm{~mm}$ 캐뉼러 두 개, 내시경 삽입을 위한 $10 \mathrm{~mm}$ 캐뉼러 하나를 사용한다. 처음 수 술 공간을 만들 때 hydro-dissection을 하기 위해 Veress needle을 사용하고, vascular tunneller와 Kelly clamp 같은 끝이 뾰족하지 않은 기구들을 이용하여 수술 공간을 넓힌다 (Fig. 1). 절제된 검체는 내시경용 주머니(endoscopic pouch) 에 넣어서 제거한다.

\section{환자 준비}

저자는 일반적으로 근전도(electromyogram) 튜브를 사용 해 경구기관삽관을 통해 전신마취를 한다. 튜브는 좌우측 입 가장자리에 고정하여(마취 장비와 같은 방향) 수술 중에 빠지 지 않게 한다. Anuwong을 비롯한 여러 저자들은 수술 중 구 강의 튜브가 수술을 방해하거나 빠지는 것을 예방하기 위해 경비기관삽관을 한다고 하였다. ${ }^{6,10,16)}$ 저자도 초기에는 경비 기관삽관을 하였으나 이후 경구기관삽관으로 변경하였으며,
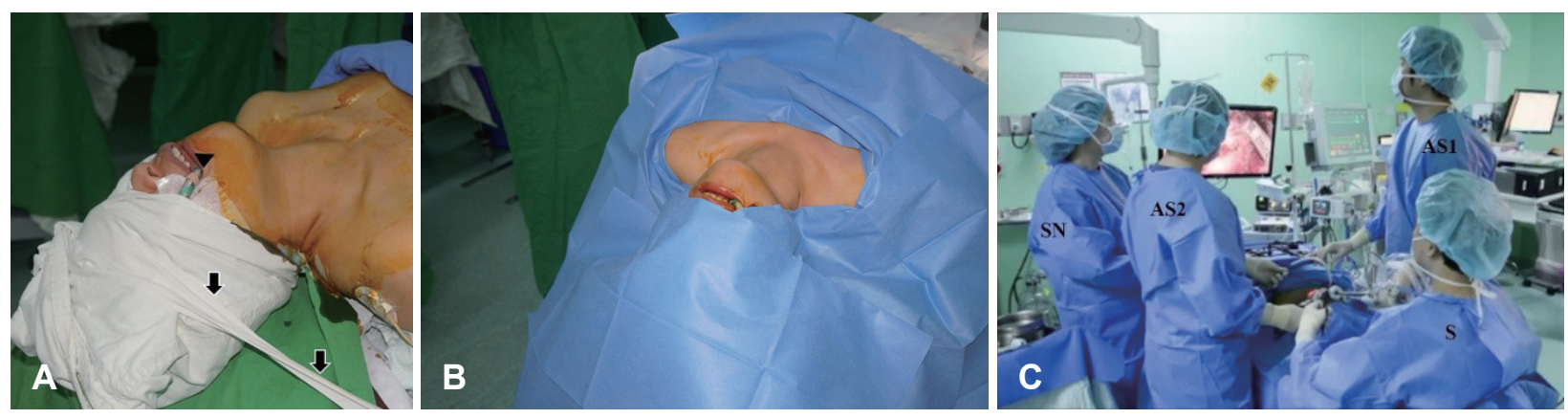

Fig. 2. Patient's position. The patient's head is fixed to the bed firmly using adhesive plaster so that the head does not turn during surgery (arrows, arrowhead: orotracheal tube) (A). The usual draping is done so that the upper lip is sufficiently exposed superiorly and the sternal notch inferiorly (B). Surgical team consists of four medical staff (C). S: surgeon (operator), AS1: first assistant surgeon, AS2: second assistant surgeon, SN: scrub nurse. 
변경 후 수술을 방해하거나 문제를 일으킨 경우는 없었다. ${ }^{9)}$ 환자의 자세는 앙와위를 취하게 하고 등 밑에 베개를 넣어 목 이 약간 신전 되도록 한다. 환자의 머리를 접착반창고로 침대 에 단단히 고정하여 수술 중 머리가 돌아가지 않도록 한다 (Fig. 2A), 구강과 경부 전방부를 포비돈 용액(povidine/water solution)으로 소독한다. 수술 부위 준비는 일반적인 방법으 로 시행하며 위로는 윗입술이, 아래로는 흥골절흔(sternal notch)이 충분히 노출되게 한다(Fig. 2B). 집도의, 보조의사 2 명, 간호사(scrub nurse)로 이루어진 4명의 의료인이 수술을 한다. 집도의가 환자의 머리 쪽에 위치하고 보조의사가 양옆 에, 간호사는 환자의 다리 쪽에 위치한다(Fig. 2C).

\section{이산화탄소 가스 사용}

이산화탄소 색전증을 예방하기 위해서 이산화탄소를 낮은 압력으로 주입하는 것이 매우 중요하다. ${ }^{18)}$ 저자는 이산화탄소 의 초기압력을 $6 \mathrm{~mm} \mathrm{Hg}$ 가 넘지 않게 하며 수술 중에는 보통 3 4 mm Hg 정도로 유지하고, 유량(flow rate)은 $12 \mathrm{~L} / \mathrm{min}$ 으 로 설정한다. Anuwong ${ }^{19)}$ 은 유량을 $15 \mathrm{~L} / \mathrm{min}$ 로 설정하고 가 스 압력은 $6 \mathrm{~mm} \mathrm{Hg}$ 를 초과하지 않아야 한다고 하였으며, 갑 상선 종양이 큰 경우에는 넓은 공간 확보를 위해 유량을 20 $\mathrm{L} / \mathrm{min}$ 정도로 높일 수 있다고 하였다. 마취과 의사와 긴밀히 협력하여 호기 말 이산화탄소 분압(end-tidal carbon dioxide, $\mathrm{ETCO}_{2}$ )을 지속적으로 측정하며 가능하면 $40 \mathrm{~mm} \mathrm{Hg}$ 를 초 과하지 않도록 한다. 이산화탄소의 흡수율은 담낭 수술 등
복강경 수술을 할 때(이산화탄소를 복강내 주입할 때)보다 갑상선 내시경 수술을 할 때(이산화탄소를 복강외 주입할 때) 더 높게 나타나므로 주의해야 한다. ${ }^{20)} \mathrm{ETCO}_{2}$ 측정은 가 스 색전증을 진단하는 데 매우 민감하고 비침습적인 좋은 방 법이다. 이산화탄소 색전이 발생하면 $\mathrm{ETCO}_{2}$ 수치가 증가하 거나 감소할 수 있다. $\mathrm{ETCO}_{2}$ 의 일시적인 증가는 혈중에 용 해된 이산화탄소의 증가 때문이며 $\mathrm{ETCO}_{2}$ 의 급격한 감소는 색전이 폐 혈관계의 일부를 막아서 발생한다. ${ }^{21)}$ 이산화탄소 색 전을 예방하기 위한 프로토콜이 아직까지는 명확히 확립되지 않았다. 저자는 수술 도중에 $\mathrm{ETCO}_{2}$ 가 $40 \mathrm{~mm} \mathrm{Hg}$ 이상으로 올라가면 일단 $\mathrm{CO}_{2}$ 가스 압력을 낮추어 보고, 그래도 $\mathrm{ETCO}_{2}$ 가 $40 \mathrm{~mm} \mathrm{Hg}$ 미만으로 떨어지지 않으면 수술을 중단하고 $\mathrm{CO}_{2}$ 가스 밸브를 막고 $\mathrm{ETCO}_{2}$ 가 떨어질 때까지 기다린다. 수 술이 끝나고 나면 이산화탄소 관련 합병증을 항상 염두에 두 어야 한다. 환자에게 마스크를 통해 산소를 공급하고, 호흡 곤란의 징후를 점검하며, 피하기종을 확인한다.

\section{수술 공간의 확보}

잇몸에서 $1 \mathrm{~cm}$ 떨어진 전정 중앙에, Bovie를 이용하여 $2 \mathrm{~cm}$ 의 곡선 절개를 만들고, 안쪽으로 박리하여 턱끝근(mentalis muscle)의 내측 부분을 절개하여 하악의 아래쪽 경계가 노 출되도록 한다(Fig. 3A), 하악의 아래쪽 경계가 노출되면 Veress needle을 사용하여 40 50 mL의 생리식염수를 활경 근 아랫면(subplastysma plane)에 주입하여 수술 공간을 확
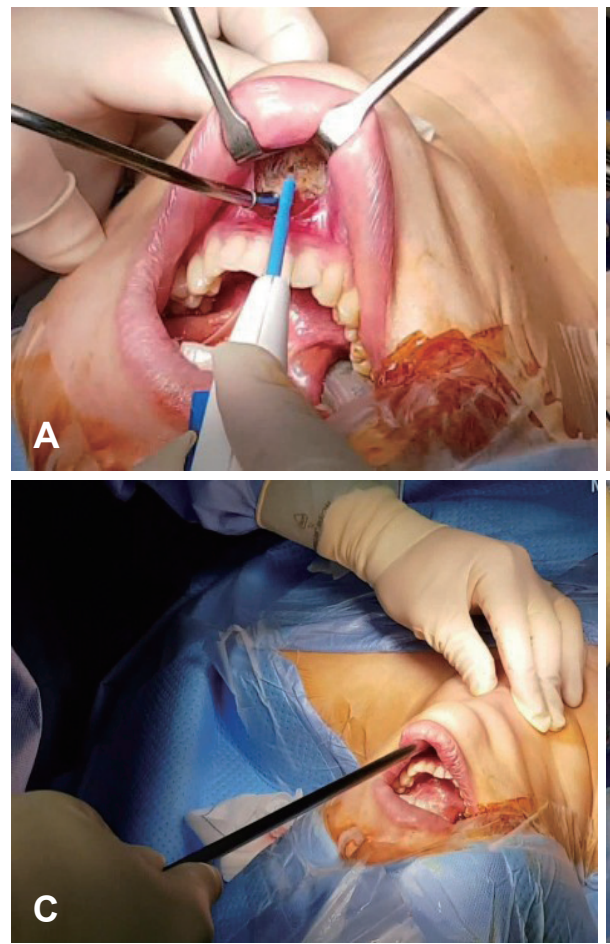

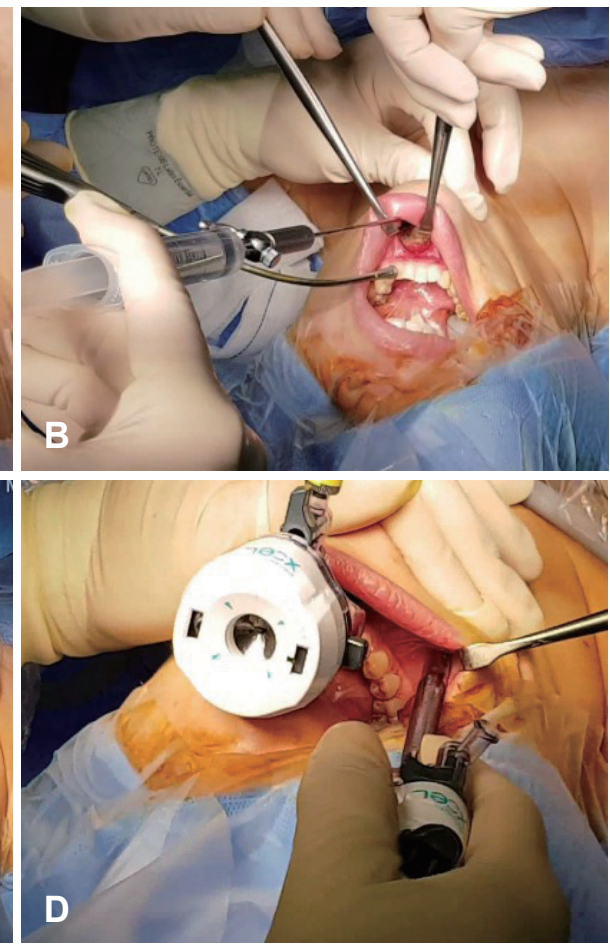

Fig. 3. Creation of a working space for transoral endoscopic thyroidectomy. A 2-cm-long curvilinear incision in the midline of the vestibule (A). Injection of normal saline into the subplatysmal space to widen the space (B). Widening of the working space in the submental and anterior neck using a blunt instrument (C). Insertion of 5-mm-diameter cannula through right lateral incision in the vestibule near the first molars (D). 
보한다(hydro-dissection)(Fig. 3B). Kelly clamp를 사용하여 턱끝밑(submental)의 작업 공간을 조심스럽게 넓힌다. 다음으 로, vascular tunneller와 같은 끝이 뾰족하지 않은 기구를 절 개 부위를 통해 삽입하여 활경근 아랫면에서 부채꼴 형태로 박리하여 역삼각형 모양의 수술 공간을 만들어 준다(Fig. $3 \mathrm{C}$. 즉, 흥골절흔(sternal notch)이 하단 경계를 이루고 양쪽 흥쇄유돌근(sternocleidomastoid) 앞쪽 선이 측면 경계를 이 룬다. 직경 $10 \mathrm{~mm}$ 캐뉼러를 삽입하여 이산화탄소 가스를 압 력 $6 \mathrm{~mm} \mathrm{Hg}$, 유속 $12 \mathrm{~L} / \mathrm{min}$ 로 유지한다. $10 \mathrm{~mm}, 30^{\circ}$ 내시 경을 캐뉼러에 삽입하여 수술 공간이 잘 형성되었는지 확인 한다. 다음으로, 제 2 소구치와 제 1 대구치 근처 전정에 양쪽 측면 절개를 하고, 각 절개를 통해 직경 $5 \mathrm{~mm}$ 캐뉼러를 삽입 한다(Fig. 3D). 턱끝신경(mental nerve)이 턱끝구멍(mental foramen: 제 1 소구치와 제 2 소구치 사이 정도에 위치)에서 나 와 앞쪽으로 주행하므로 이보다 후방에 측면 절개를 가하는 것이 안전하다. Maryland forceps, L-hook 소작기와 초음파 장비를 각 측면 캐뉼러로 삽입하여 활경근 아랫면을 따라 하 방으로 흥골절흔까지, 양쪽 측면으로 흥쇄유돌근까지 수술 공간을 확장한다.

\section{갑상선 협부와 상극의 박리}

초음파 절삭기, L-hook 소작기를 이용하여 피대근(strap muscle)의 중앙봉선(median raphe)을 분리하여 갑상선 협 부를 노출시키고 피대근을 갑상선에서 분리한다(Fig. 4A). 경부 피부로부터 2-0 black silk를 삽입하고 피대근을 관통 해서 다시 경부로 빼낸 후에 측면으로 당겨서 갑상선을 노출
시킨다(개방 갑상선 수술에서 피대근을 Army와 Navy로 견 인하는 것과 같은 효과가 있다). 박리를 내측으로 진행하여, 초음파 절삭기를 이용하여 협부를 절제한다. 이후, 기구를 외 측으로 옮겨 무혈관 흥골설골-후두삼각(sternohyoid-laryngeal triangle)을 확인하고 상극을 Babcock이나 Johann forceps로 잡아 내측으로 당겨서 상갑상선 혈관을 노출시킨다. 이어서 초음파 절삭기를 이용하여 상갑상선 혈관을 절제한다 (Fig. 4B)

\section{반회후두신경과 부갑상선}

중간 갑상선 정맥을 분리한 후, 갑상선을 내측으로 당긴다. 갑상선이 내측으로 견인된 상태에서 기관-식도 고랑과 하갑 상선동맥이 쉽게 노출된다. 내시경의 확대된 시야를 통해, 부 갑상선, 반회후두신경 및 경동맥을 비롯한 모든 해부학적 중 요 구조물을 확인하고 보존한다(Fig. $4 \mathrm{C}$ and D). 갑상선을 전 방으로 견인한 후, Berry’s 인대를 기관으로부터 박리하고 갑 상선 일측 엽을 완전히 제거한다.

\section{검체 제거와 봉합}

검체를 내시경 주머니에 넣고 정중선 절개부를 통해 제거 한다. 구강내 측면 절개부를 통해 배출관(negative suction drain)을 삽입한다. Anuwong 등은 일반적으로 갑상선 엽절제 술을 할 때에는 배출관을 삽입하지 않으며 갑상선 전 절제술 에만 삽입한다고 언급하였다. ${ }^{6,16}$ 저자는 수술 공간에 seroma 가 발생한 환자들을 4명 경험한 이후로 모든 환자에게 배출 관을 삽입하여 24시간 유지하고 있다. 정중앙에서 피대근을
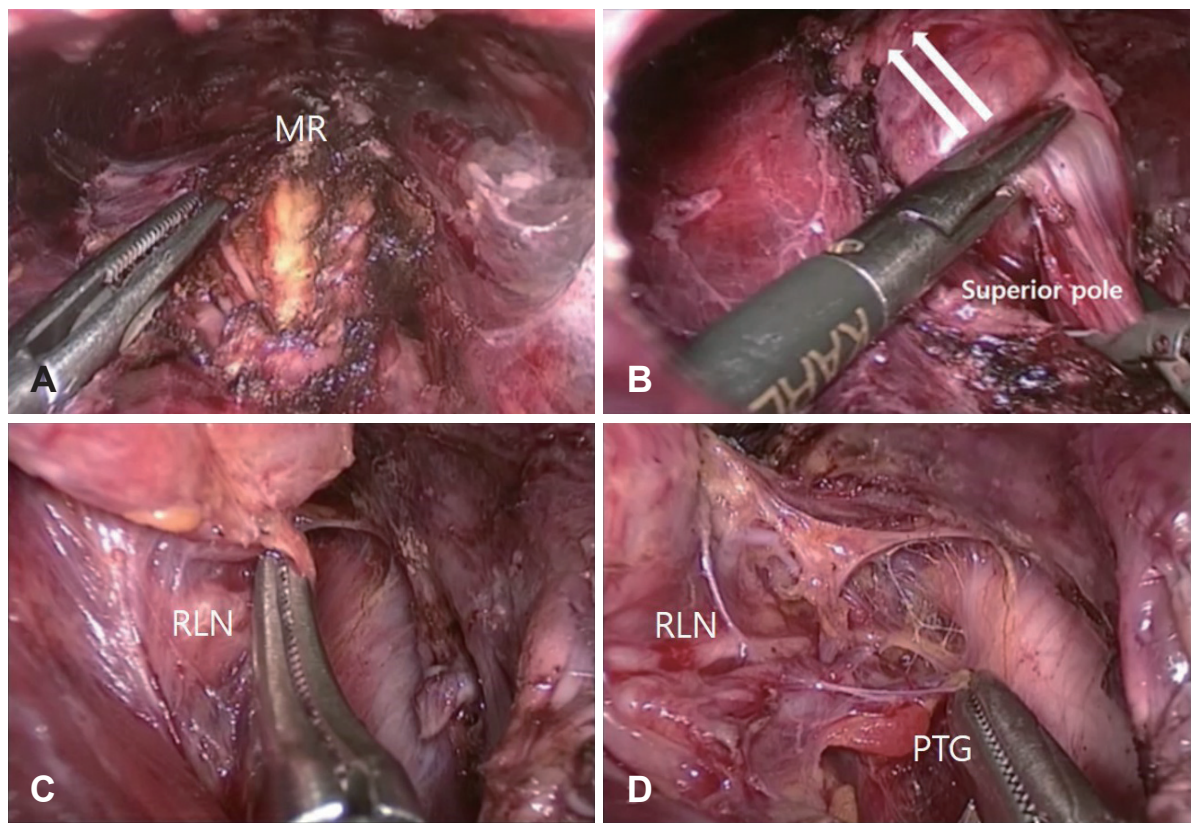

Fig. 4. Transoral endoscopic right thyroid lobectomy. Division of the MR (A). Division of the superior lobe (arrows: the direction of traction) (B). Identification of the RLN (C). Identification of all the important anatomical structures such as RLN and PTG (D). MR: median raphe, RLN: recurrent laryngeal nerve, PTG: parathyroid gland. 
다시 봉합하고 흡수성 봉합사로 세 개의 절개부를 봉합한다.

\section{술 후 관리}

탄력붕대를 사용하여 턱과 목 주변에 압박 드레싱을 하고 48시간 후에 제거한다. 배출관은 일반적으로 24시간 후에 20 25 mL/day 이하이면 제거한다. 수술 후에 환자들에게 마스크로 산소를 공급하고, 호흡곤란의 징후를 점검하며, 피 하기종을 확인한다. 수술 당일에는 부드러운 음식(미음이나 죽)을 제공하고, 술 후 1,2 일째에는 일반식을 제공하였다. 입 원 기간 동안 정맥 항생제를 투여하고 퇴원 후 경구 항생제 를 처방한다. 구강점막 봉합물은 일반적으로 첫 외래 방문할 때 제거한다.

\section{결 론}

갑상선 구강내시경 수술은 앞으로 지속적인 검증이 필요하 겠지만 여러 가지 장점이 기대되는 접근법이라고 생각된다. 이 수술의 가장 큰 이점은 점막 절개만으로 수술을 할 수 있으 므로 피부 절개로 인한 비후성 반흔, 색소침착과 같은 합병 증의 위험이 없다는 것이다. 다른 내시경 접근과 비교할 때, 갑상선에 최단 경로로 접근하며 정중앙으로 내시경이 삽입 되므로 갑상선 전 절제술에 가장 적합하다고 생각된다. 앞으 로 수술 술기를 더 세밀하게 다듬고 정형화한다면 향후 갑상 선 수술에 최선의 선택이 될 수 있을 것으로 기대된다.

\section{Acknowledgments}

This work was supported by the National Research Foundation of Korea(NRF) grant funded by the Korea government (No. NRF2014R1A2A2A03004802).

\section{REFERENCES}

1) Moris DN, Bramis KJ, Mantonakis EI, Papalampros EL, Petrou AS, Papalampros AE. Surgery via natural orifices in human beings: yesterday, today, tomorrow. Am J Surg 2012;204(1):93-102.

2) Wilhelm T, Metzig A. Endoscopic minimally invasive thyroidectomy (eMIT): a prospective proof-of-concept study in humans. World J Surg 2011;35(3):543-51.

3) Wang Y, Xie QP, Yu X, Xiang C, Zhang ML, Zhao QZ, et al. [Preliminary experience with transoral endoscopic thyroidectomy via vestibular approach: a report of 150 cases in a single center]. Zhonghua Wai Ke Za Zhi 2017;55(8):587-91.
4) Karakas E, Steinfeldt T, Gockel A, Westermann R, Kiefer A, Bartsch DK. Transoral thyroid and parathyroid surgery. Surg Endosc 2010;24 (6):1261-7.

5) Nakajo A, Arima H, Hirata M, Mizoguchi T, Kijima Y, Mori S, et al. Trans-oral video-assisted neck surgery (TOVANS). a new transoral technique of endoscopic thyroidectomy with gasless premandible approach. Surg Endosc 2013;27(4):1105-10.

6) Anuwong A. Transoral endoscopic thyroidectomy vestibular approach: a series of the first 60 human cases. World J Surg 2016;40(3):491-7.

7) Chai YJ, Chung JK, Anuwong A, Dionigi G, Kim HY, Hwang KT, et al. Transoral endoscopic thyroidectomy for papillary thyroid microcarcinoma: initial experience of a single surgeon. Ann Surg Treat Res 2017;93(2):70-5.

8) Dionigi G, Tufano RP, Russell J, Kim HY, Piantanida E, Anuwong A. Transoral thyroidectomy: advantages and limitations. J Endocrinol Invest 2017;40(11):1259-63.

9) Park JO, Sun DI. Transoral endoscopic thyroidectomy: our initial experience using a new endoscopic technique. Surg Endosc 2017;31 (12):5436-43.

10) Dionigi G, Bacuzzi A, Lavazza M, Inversini D, Boni L, Rausei S, et al. Transoral endoscopic thyroidectomy: preliminary experience in Italy. Updates Surg 2017;69(2):225-34.

11) Peng XW, Li H, Li Z, Zhou X, Song DJ, Zhou B, et al. Modified transoral endoscopic thyroid surgery for treatment of thyroid cancer: operative steps and video. Gland Surg 2017;6(6):742-4.

12) Kim HY, Chai YJ, Dionigi G, Anuwong A, Richmon JD. Transoral robotic thyroidectomy: lessons learned from an initial consecutive series of 24 patients. Surg Endosc 2018;32(2):688-94.

13) Jitpratoom P, Ketwong K, Sasanakietkul T, Anuwong A. Transoral endoscopic thyroidectomy vestibular approach (TOETVA) for Graves' disease: a comparison of surgical results with open thyroidectomy. Gland Surg 2016;5(6):546-52.

14) Chai YJ, Kim HY, Kim HK, Jun SH, Dionigi G, Anuwong A, et al. Comparative analysis of 2 robotic thyroidectomy procedures: transoral versus bilateral axillo-breast approach. Head Neck 2017 Dec 14 [Epub ahead of print]. https://doi.org/10.1002/hed.25034.

15) Razavi CR, Russell JO. Indications and contraindications to transoral thyroidectomy. Ann Thyroid 2017;2(5). pii: 12.

16) Anuwong A, Sasanakietkul T, Jitpratoom P, Ketwong K, Kim HY, Dionigi G, et al. Transoral endoscopic thyroidectomy vestibular approach (TOETVA): indications, techniques and results. Surg Endosc 2018;32(1):456-65.

17) Razavi CR, Fondong A, Tufano RP, Russell JO. Central neck dissection via the transoral approach. Ann Thyroid 2017;2(5). pii: 11.

18) Kim SH, Park KS, Shin HY, Yi JH, Kim DK. Paradoxical carbon dioxide embolism during endoscopic thyroidectomy confirmed by transesophageal echocardiography. J Anesth 2010;24(5):774-7.

19) Anuwong A. Strategy to prevent subcutaneous emphysema and gas insufflation-related complications in transoral endoscopic thyroidectomy vestibular approach: reply. World J Surg 2017;41(10):2649-50.

20) Cunningham AJ. Laparoscopic surgery--anesthetic implications. Surgical endoscopy. Surg Endosc 1994;8(11):1272-84.

21) Park EY, Kwon JY, Kim KJ. Carbon dioxide embolism during laparoscopic surgery. Yonsei Med J 2012;53(3):459-66. 


\section{정답 및 해설}

1. 답 (3)

해 설 Frey 증후군을 예방하기 위해서는 피하지방을 피부에서 두껍게 붙여 두는 것이 유리하다.

참고문헌: 대한갑상선두경부외과학회. 갑상선·두경부외과학. 서울: 범문에듀케이션;2014. p.389-99.

2. 답 (3)

해 설 첫 24시간은 흉부 X-ray가 민감도와 특이도가 가장 낮다. 특별한 기도 이물 흡인 병력이 없더라도 증상과 흉부 CT 소견 으로 보아 좌측 기관지의 기도 이물을 충분히 의심할 수 있다. 대부분의 기도 이물은 후두나 기관에 위치하는 경우는 드 물며 기관지에 주로 발생한다. 이물질이 기도를 완전히 폐쇄하지 않고 적절하게 호흡이 가능한 환자라면 하임리히 요법 등을 시도하면 완전 폐색을 초래할 수 있으므로 삼가는 것이 좋다.

참고문헌: 대한소아이비인후과학회. 소아이비인후과학. 파주: 군자출판사;2016. p.509-21. 